\title{
FOTOGRAFIA E RITUAL: ENSAIO SOBRE OS HOMENS E AS IMAGENS DA PAIXÃO
}

Edilson Pereira ${ }^{1}$

UFRJ, Rio de Janeiro-RJ, Brasil

\begin{abstract}
Apresento neste foto-ensaio o percurso da pesquisa etnográfica realizada sobre a Semana Santa em Ouro Preto, Minas Gerais, e seu posterior desdobramento ao acompanhar a mesma festa na cidade de Sevilha, Espanha. Analiso a preeminência das imagens no contexto ritual e descrevo a utilização das ferramentas de pesquisa audiovisuais, com destaque para a fotografia. Debato os limites da mensagem fotográfica considerando não só o que elas apresentam, mas também o que podem ocultar, e passo a observar a performance ritual dos "costaleros" de Sevilha: os homens que são responsáveis por carregar as imagens religiosas em procissão. Como atores de um teatro às avessas, eles atuam na parte interna, oculta, dos andores que destacam as figuras cristãs.

Palavras-chave: Semana Santa, Espanha, religião, performance, fotografia, antropologia visual
\end{abstract}

Este é um foto-ensaio baseado no estudo da atuação das imagens religiosas e fotográficas vinculadas aos rituais da Semana Santa em dois contextos etnográficos. Partindo dos resultados de uma pesquisa de campo realizada no interior de Minas Gerais (Pereira 2010; 2014; 2014a), descreverei a relevância socialmente conferida às imagens sacras nesse ambiente para, em seguida, traçar alguns paralelos com o repertório observado no estudo da celebração da Paixão de Cristo ao sul da Espanha. Ao abordar a festa sevilhana, articulo os resultados de uma investigação de caráter biblio-fotográfico, incluindo a literatura especializada e um acervo digital de compartilhamento de imagens, para analisar não apenas as figuras sacras, mas igualmente os registros e imaginários produzidos sobre elas. Considerando que a macronarrativa religiosa pode ser continuamente ressignificada em cada contexto onde seja reencenada, apresento as condições de pesquisa que guiaram a produção das minhas fotografias nos dois campos, com destaque final para os costaleros sevilhanos. A ênfase nesses personagens deve-se ao desafio de fotografá-los em sua ação ritual nas procissões da Semana Santa (Pereira 2018).

1 Contato do autor: edilson.pereira@eco.ufrj.br 
Veja a galeria de fotos aqui:

https://journals.openedition.org/cadernosaa/3286

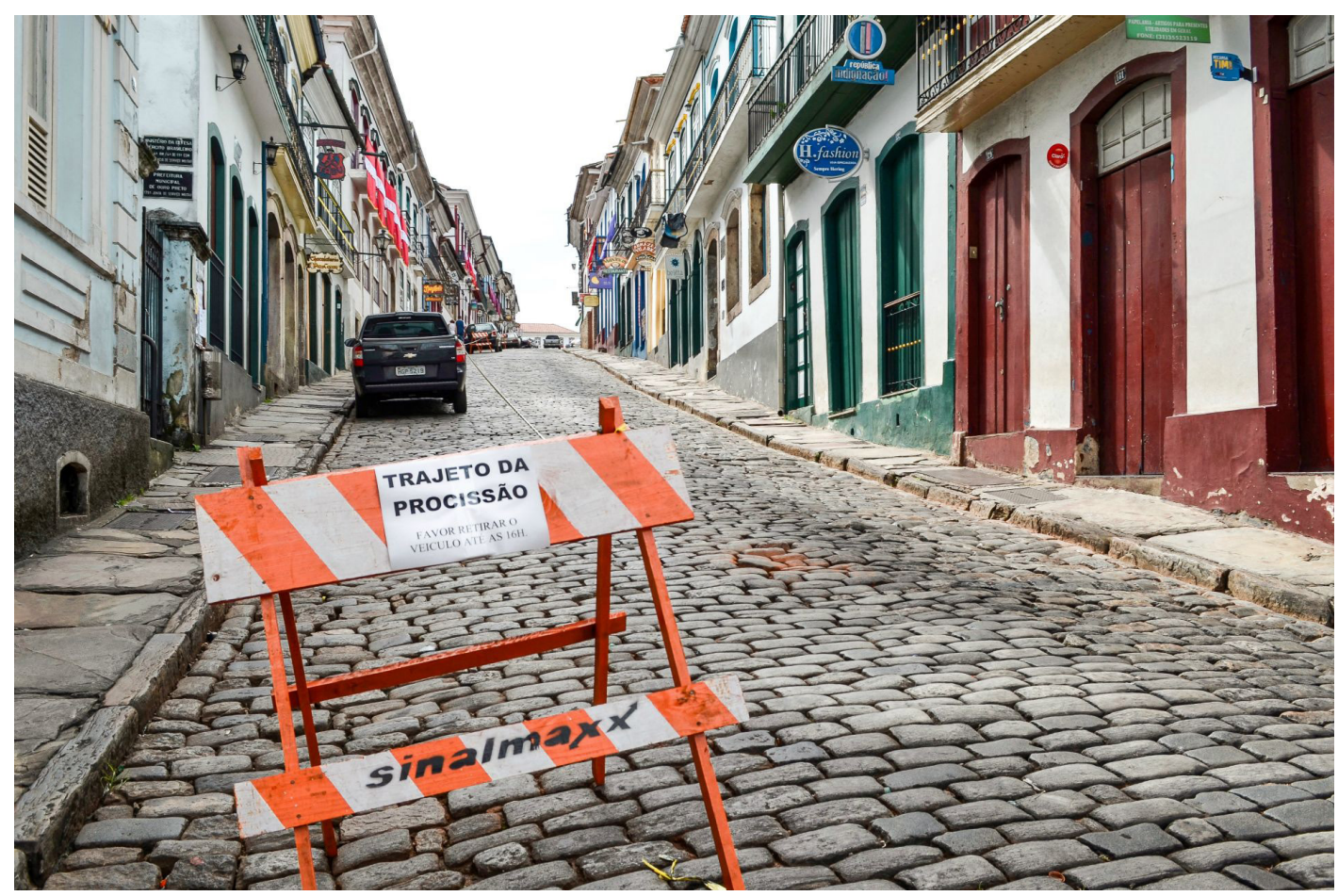

\section{IMAGENS DA PAIXÃO: O BARROCO}

"O que é a porta? Um vão. Mas um vão que separa dois domínios: o domínio dos deuses e o dos mortais - a porta do templo". Era assim que Roger Bastide iniciava seu texto a propósito da porta barroca (2016:130), artigo no qual ele recupera autores clássicos como Arnold van Gennep para enfatizar o caráter de transformação simbólica que acompanhava a ação de atravessar os pórticos religiosos. Ao descrever em detalhes a arquitetura e a estética de igrejas do nordeste brasileiro, Bastide afirmava que sua ornamentação correspondia a uma maneira de separar o espaço civil do sagrado, a materialidade da porta como uma "cristalização na pedra do cerimonial de entrada ou de saída" (loc.sit.).

Quando iniciei minha pesquisa de doutorado a respeito da celebração da Semana Santa no interior de Minas Gerais, nos idos de 2009, um dos aspectos relacionados à festa que chamava a atenção era justamente o movimento de saída das igrejas feito por atores que, no resto do tempo, permaneciam ativos dentro do espaço religioso. Na época de rememorar a passagem (Pessach) entre a morte e a ressurreição do filho de Deus tornado homem, os sacerdotes, os fiéis e as imagens barrocas de Cristo e de Nossa Senhora saem às ruas e ressignificam os espaços da vida urbana. Junto com os moradores que se vestem como personagens bíblicos, em procissão, eles atravessam praças e ladeiras da cidade que passam a servir de cenário para dramatizar eventos de uma Jerusalém de dois mil anos atrás.

Nessa dinâmica, era interessante notar a alteração das relações estabelecidas com as imagens religiosas. Em cidades como Ouro Preto, muitas figuras tridimensionais que ornamen- 
tam as igrejas barrocas integram também os acervos dos museus de arte sacra. Em geral, esses museus são orientados por uma perspectiva de preservação e salvaguarda dos "bens culturais" classificados como peças de arte religiosa, atuando de forma a prevenir que sua integridade material e estética seja posta em risco. Para tanto, eles exibem as imagens, ao longo do ano, em altares ou vitrines que impossibilitam o contato humano direto, fazendo com que elas possam ser acessadas apenas pela visão de devotos e turistas.

$\mathrm{Na}$ época da festa, em contrapartida, as imagens passam a representar determinadas cenas da Paixão de Cristo e atuam como objetos de devoção capazes de mobilizar centenas de pessoas que se dirigem a elas para tocá-las, beijá-las e falar com os santos ali apresentados. Sendo o barroco "o reino da festa perpétua (até mesmo a morte é motivo de festa)", ou o "reino da representação" como dizia Bastide (idem: 134), as imagens sacras desempenham nele um papel-chave: elas são elevadas a protagonistas dos rituais que rememoram eventos centrais da cosmologia religiosa.

No caso de Ouro Preto, as imagens utilizadas nos rituais católicos remetem também a histórias que recontam um mito de formação da própria cidade. $\mathrm{Na}$ tradição local, as cerimônias públicas e procissões que caracterizam a Semana Santa são organizadas por duas paróquias centrais, Antônio Dias e Pilar - ambas localizadas no perímetro urbano tombado pelo Patrimônio histórico e artístico nacional. Essas paróquias se alternam temporalmente na organização das cerimônias que ocorrem no espaço público, o Pilar celebrando a Semana Santa dos anos pares $(2020,2022,2024 \ldots)$ e o Antônio Dias dos anos ímpares (2021, 2023, 2025...). De acordo com os moradores, a forma de celebrar a paixão de Cristo no presente resultaria de uma clivagem histórica, produzida no início do Ciclo do Ouro em Minas.

No passado, o território das atuais paróquias correspondia a dois arraiais distintos que disputavam entre si o monopólio da mineração. Antônio Dias era o nome de um bandeirante paulista que se contrapunha aos "emboabas", isto é, aos forasteiros, incluindo portugueses e nativos do litoral brasileiro que se deslocaram à região interessados em suas riquezas. Os portugueses, por sua vez, concentravam-se no arraial de Ouro Preto, cuja padroeira era Nossa Senhora do Pilar. Apesar de circunscrito ao início do século XVIII, as consequências diretas daquele conflito perdurariam por muito tempo. Segundo a historiadora Adriana Romeiro (2009:15), "a Guerra dos Emboabas, apesar de encerrada em 1709, continuaria viva por todo o século XVIII, alimentando os velhos ódios entre paulistas e emboabas, acirrando as divisões culturais e históricas, inflamando, com seu rastro explosivo, a vida política daquela que seria a capitania mais conturbada do Império português."

O antigo conflito conformaria, assim, a forma atual de realização da festa. Ele sustentaria uma importante assimetria mantida historicamente entre as paróquias: apenas a paróquia do Pilar, que corresponde ao lado vencedor da guerra, teve condições de importar da Europa uma imagem barroca de Cristo para encenar a via-crúcis na Semana Santa. Embora cada paróquia possua seu próprio exemplar de Nossa Senhora das Dores, que representa a mãe de Jesus, o único Senhor dos Passos na cidade pertence ao Pilar de Ouro Preto. Assim, a imagem religiosa que é focalizada anualmente por ocasião de um ritual coletivo atua como signo de uma hierarquia social vinculada à história da cidade. Junto a essa dupla constituição semântica da imagens, acrescenta-se ainda o fato de que elas são tomadas como índices da "tradição" - cultural, religiosa, artística - que mobiliza turistas de várias partes do país e do exterior para acompanhar a Semana Santa "barroca" de Ouro Preto. Por isso, as imagens podem ser compreendidas como 
símbolos rituais dominantes (Turner, 2005) capazes de condensar vários significados a partir de uma materialidade que, por sua vez, articula-se a um repertório sensorial que comunica algo.

\section{IMAGENS DA PAIXÃO: O FOTOGRÁFICO}

Dada a centralidade das imagens religiosas no universo estudado na época do doutorado, busquei então me aproximar das ferramentas de pesquisa da antropologia visual com a intenção de produzir um corpus de dados que permitisse manter algo da riqueza estética dos rituais, sem reduzi-los ao formato de um texto. Por conta da ênfase na visualidade e dos estímulos sensoriais próprios da festa, o uso de tecnologias de captação de imagem parecia ser essencial para documentar cenas e detalhes do que ocorria em campo. Outro fator que colaborava na minha iniciação antropológica com as imagens derivava das próprias interações mantidas em campo com um grupo de fotógrafos profissionais de Ouro Preto. Eles detinham conhecimentos que eu ainda não dominava e sabiam quais eram os melhores pontos da cidade para se fazer "belas" imagens, nas quais a paisagem colaborava no enquadramento. $\mathrm{O}$ contato com esses interlocutores foi importante para estimular o meu uso da fotografia e o consequente acúmulo de registros ao longo da pesquisa.

As trocas mantidas em campo ajudaram a me familiarizar com uma linguagem e com técnicas que eu conhecia apenas de modo amador. E, com o avançar do tempo, o uso metodológico da fotografia foi se transformando conforme eu passei a manipular a câmera com mais confiança. Aos poucos, relação com a fotografia foi deixando de ser uma prática voltada unicamente à descoberta ou descrição de algo - como modo de documentar os múltiplos estímulos sensoriais dos rituais - para se converter em uma forma de narrar (Guran 2012). Após cinco anos de pesquisa, havia acumulado dezenas de horas de vídeo e mais de 4.600 fotografias das pessoas, artefatos e eventos que compõem a festa - expondo alguns desses registros em eventos científicos de antropologia (Pereira 2010; Pereira 2014a).

Nessa dinâmica, a observação de práticas rituais, com seus símbolos e materialidades, passou a orientar não só o conteúdo apresentado nas fotografias, mas a própria forma de fazê-las. Ao fim do doutorado, compreendi que as estéticas nativas não eram apenas conteúdos estáveis que se colocavam à mercê de um registro antropológico, logo científico, a ser capturado por tecnologias supostamente neutras. Em um contexto no qual performances são feitas para serem vistas, como no caso exemplar dos cortejos religiosos, nenhuma imagem é neutra. Assim, as fotografias feitas para serem mostradas em campo e fora dele passaram a ser elaboradas como parte de uma linguagem que não só lida com outra (a religiosa e ritual, observada durante a Semana Santa), mas que deve produzir um tipo de encontro com ela, repensando estéticas e lógicas de produção de conhecimento nos moldes de uma antropologia compartilhada. Em suma, compreendi que a fotografia fazia parte da encenação que ajudava a retratar e que, por consequência, eu participava daquele jogo de ver e ser visto que articula realidade e ficção, conforme discuti em outro momento (Pereira 2019). 


\section{OUTRAS IMAGENS, DO BRASIL À ESPANHA}

A pesquisa do doutorado gerou um aprendizado a respeito das imagens religiosas e fotográficas ao colocá-las no foco da atenção, sem tomar como óbvias as suas funções e capacidade de engajar nossa imaginação. Ambas permitem estabelecer relações através do olhar. Esse ensinamento auto-reflexivo foi importante na elaboração do projeto para o pós-doutorado que seria realizado poucos anos depois, na Espanha ${ }^{2}$. Com o intuito de alargar o escopo de análise produzido em Minas Gerais, propus um levantamento bibliográfico que permitisse comparar, a partir do cenário europeu e espanhol, as maneiras de lidar com artefatos/símbolos - como as imagens religiosas - que transitam entre registros rituais, artísticos, históricos e do patrimônio. A princípio, o interesse da pesquisa era ampliar o conhecimento para além das festas, buscando casos nos quais a imagem religiosa pudesse estar enredada em formas seculares de sacralização, inclusive como objeto de culto artístico (Duncan 2008).

Porém, logo nos primeiros meses do levantamento bibliográfico, era notável a reincidência de obras voltadas à análise das imagens na Semana Santa espanhola, sobretudo das regiões da Andaluzia e de Valência. Com o progressivo acúmulo de referências, as informações a respeito de cidades como Sevilha passaram a ocupar o centro da atenção no pós-doc. No processo de pesquisa, os trabalhos de história, de história da arte e de antropologia convergiam entre si ao apontar que a Semana Santa desempenhava um papel importante no imaginário consolidado sobre o sul espanhol (Conf. Albert-Llorca 1995; Webster 1998; Santaló, Rey \& Rodríguez 2003; Teulade 2012; Rodríguez \& Bermúdez 2012; entre outros). Nesse momento, já era possível constatar uma recorrência em relação ao campo realizado no Brasil. Tanto lá como cá, a celebração religiosa era vista como um meio eficaz de mobilizar memórias e sentimentos coletivos, servindo para dramatizar aspectos da identidade local - fosse para próprios moradores ou para os turistas e viajantes interessados na estética e forma particular de comemorar um período sensível no calendário católico. No caso sevilhano, a Semana Mayor é classificada como "Fiesta de Interés Turístico Internacional" pelo governo espanhol desde os anos 1980, chegando a atrair atualmente mais de 100 mil turistas por ano.

Em comparação com Ouro Preto, havia também uma grande atenção conferida às imagens sacras - ainda que o caso espanhol demandasse uma nova escala de observação, posto o número bem maior de turistas, moradores e de imagens mobilizadas na Semana Santa andaluza. Carregadas no alto dos andores, chamados de pasos, diversas efígies barrocas são retiradas do interior das suas igrejas e levadas em procissão por diferentes bairros, passando sempre pela centenária catedral de Sevilha antes de voltar aos seus locais de origem. Expostas de modo a mimetizar as cenas bíblicas, as figuras espanholas intensificam o estilo realista, de verossimilhança ao humano, presente nas réplicas de Minas Gerais.

Uma interessante diferença em relação ao contexto de pesquisa brasileiro residia, entretanto, na existência de uma história visual consolidada a respeito das representações dos rituais espanhóis - incluindo gravuras, fotografias e filmes feitos sobre eles. Em "El reflejo de la Semana Santa de Sevilla a través del cinematógrafo (1898-1960)", o historiador de arte Antonio García Baeza (2017) aponta que em 1896, apenas um ano após o patenteamento do cinema pelos irmãos Lumière, já se registravam imagens de procissões locais. Em relação à fotografia,

2 A pesquisa foi realizada no Departamento de Antropologia da Universitat de Barcelona, sob supervisão de Roger Sansi entre os anos de 2017 e 2018, com financiamento da CAPES. 
por sua vez, a proximidade espacial com outras cidades da Europa e a espetacularidade dos cortejos andaluzes fez com que a região se tornasse atraente aos profissionais de renome na área. Se, no momento mais recente, identificamos o trabalho fotográfico de sevilhanos como Juan Manuel Serrano (ABCdeSevilha, s/d) e David Jiménez (2003), ou da espanhola Cristina Garcia Rodero, vinculada à agência Magnum, em relação aos estrangeiros podemos citar o fotógrafo checo Josef Koudelka, que retratou a festa de 1977, o suíço-americano Robert Frank, que viajou para Valência no início dos anos 1950, além do húngaro Robert Capa e do francês Pierre Verger que acompanharam, ambos, a festa sevilhana do ano de 1935. Uma retrospectiva histórica completa demandaria um artigo próprio sobre o tema.

No caso de Pierre Verger particularmente, as fotos da Semana Santa remetem a um momento de consolidação de sua carreira profissional, iniciada poucos anos antes. O fotógrafo-antropólogo, que se mudaria para a Bahia em 1946 e produziria registros como os que acompanham o artigo de Bastide (2016) sobre a porta barroca, já citado, descrevia sua primeira viagem ao sul da Espanha como uma experiência singular. Entre os pontos altos da passagem pela Andaluzia, Verger sublinhava:

a Semana Santa em Sevilha onde se pode ver o fervor quase bárbaro que causavam os andores, pelas ruas estreitas do centro da cidade, da Virgem de la Macarena e do Jesús del Gran Poder. Era ainda a Espanha de antes da Guerra Civil, que já estava muito próxima e que iria explodir alguns meses mais tarde. (Verger, 2007:144; tradução livre)

Verger faz referência às imagens religiosas que seguem sendo alvo de grande devoção local, atuando como símbolos que delineiam parte da identidade sevilhana no presente - cada paróquia ou bairro com sua invocação particular do Cristo e da Virgem. Na parte final de sua fala, Verger nos remete ao momento histórico de proximidade com os conflitos relacionados à instauração da ditadura em solo espanhol. Entre 1936 e 1975 o país viveria intensos momentos de repressão política e cultural. Nesse período, o controle estatal sobre as mais diversas atividades recaía igualmente sobre as manifestações religiosas coletivas e na sua divulgação pública.

Como exemplo desse controle, podemos lembrar das imagens produzidas pelo fotógrafo húngaro Brassaï, pseudônimo de Gyula Halász, em viagem pela capital andaluza no início dos anos 1950. Um conjunto de 70 fotografias e textos do fotógrafo foi reunido na publicação Seville en Fête (Aubier 1954) lançada em francês e em alemão, sendo traduzida dois anos mais tarde para o inglês, mas proibida na Espanha. Assim como ocorrera anos antes com Verger, que havia sido conduzido por um policial para interrogatório após vê-lo fotografar um muro com a frase Abajo el fascismo, sendo então chamado de "subversivo" (Verger 2007:114), a obra de Brassaï se contrapunha à imagem da nação projetada pelo Estado ditatorial. $O$ fotógrafo voltava-se aos personagens anônimos, pessoas pobres e "gente de abajo", enquanto o franquismo reproduzia uma iconografia que reforçava certa leitura da celebração religiosa (Salanova s/d). Havia um sagrado oficial divulgado pelo Estado. Casos como esse nos revelam que a história visual da festa sevilhana não apresenta apenas o lado positivo das fotografias, sua porção mais evidente. Ao reforçar imaginários sobre um universo sociocultural a partir de certa expressão visual tipificada, as fotografias são capazes de desvelar formas de apagamento. Algumas histórias sendo esquecidas para destacar outras, que se tornam hegemônicas.

Ao reconhecer a existência dessa política interna às imagens, considerei necessário expandir o corpus de dados da pesquisa para tentar observar as formas contemporâneas de retratar a festa. Paralelamente ao levantamento da literatura especializada e das obras de fotógrafos 
consagrados, passei a monitorar acervos digitais de fotografias vernaculares, amadoras, como aquelas produzidas em tecnologias de grande alcance como o Instagram. Através de buscas realizadas no aplicativo com o termo-chave \#semanasantasevilla, encontrei mais de 100 mil registros (número atualizado ao momento de publicação deste texto), dos quais a vasta maioria reproduz detalhes das figuras sacras e de seu entorno mais imediato - deixando de lado outros personagens e aspectos da festa. As imagens de Cristo e da Virgem são símbolos dominantes tanto nos rituais como na linguagem visual acionada para documentar a Semana Santa.

Embora lidemos com um contexto de multiplicação de câmeras e celulares, que poderia sugerir uma ampliação do espectro de perspectivas sobre um evento de relevo na vida social de cidades como Sevilha, há modos de representação apreendidos e reproduzidos que parecem perdurar. Por essa razão, o contexto espanhol permite recolocar em questão os limites da fotografia como instrumento de atestação do real. Em verdade, conforme sintetiza Joan Fontcuberta (2013:10) tal "como na magnífica encenação da Paixão, o realismo fotográfico escondia sua traição em um beijo. Uma traição como a de Judas, anunciada e consentida, e, no entanto, terrivelmente eficaz". Mais do que o real em si, a fotografia revela modos de percepção culturalmente orientados que delineiam o que é fotografável, isto é, visível em cada contexto, atuando como agente/meio que participa da constituição de sensibilidades e memórias através de formas estéticas que exprimem certos modos de pensar.

\section{O ENSAIO "CAIXA-PRETA SEVILHANA"3}

O avançar do estudo sobre a literatura especializada e as fotografias que documentam a Semana Santa em solo espanhol culminou na alteração dos planos originalmente feitos para a pesquisa do pós-doutorado. Àquela altura, passei a considerar as condições para realização de pesquisa de campo na festa sevilhana, sabendo que ela seria sensivelmente distinta da experiência mantida no Brasil, onde o conhecimento sobre a festa se produziu ao longo de anos. A permanência em Sevilha não seria apenas mais circunscrita, cerca de 20 dias, mas colocava em preeminência certas questões de antropologia visual. Naquele momento, as imagens deveriam guiar tanto os percursos a serem feitos em campo, quanto o texto e análise que resultaria delas.

Ao chegar na cidade dias antes da festa, em março de 2018, eu carregava uma bagagem que incluía o contato prévio com a literatura sobre a festa e com parte da história do seu registro visual, fosse ele feito por fotógrafos profissionais ou por amadores, no passado e no presente. Baseado no que havia apreendido antes de chegar ao campo, decidi abdicar das lentes com zoom, escolhendo uma câmera com lente fixa (Nikon D750,50mm) para garantir que cada foto produzida resultasse de uma obrigatória aproximação dos sujeitos retratados - uma postura que visava permitir que eles notassem minha presença e reagissem a ela. Por outro lado, o uso prévio do Instagram como ferramenta de pesquisa se mostrou útil em campo, como um canal de comunicação com vários interlocutores. Após terem seus retratos feitos, muitas pessoas pediam que eles fossem compartilhados com elas - fato que geralmente ocorria ao fim do dia, após salvar os arquivos e tomar notas no caderno de campo.

3 A série fotográfica Caixa-preta sevilhana integrou as mostras e premiações da 42a Reunião anual da ANPOCS e da 31 Reunião Brasileira de Antropologia, em 2018. 
Essa rotina se manteve na véspera e nos oito dias de festa ininterrupta que englobam a Semana Santa, desde o domingo de Ramos até o de Páscoa. Na semana, realizam-se mais de sessenta procissões sucessivas em Sevilha, com cortejos que partem de diferentes regiões até o centro histórico, podendo durar mais de 12 horas seguidas. A concomitância das procissões, quilométricas, altera significativamente a mobilidade no centro urbano e a percepção mais imediata sobre a cidade - algo análogo ao que experimentamos em cidades brasileiras na época de Carnaval.

Com base no estudo feito nos meses anteriores à festa, eu estava particularmente interessado em construir alternativas à reiteração das figuras cristãs - sem desconsiderar sua relevância no contexto em questão. Assim, a observação-participante mediada pela câmera fotográfica buscava saber mais das pessoas em relação às imagens sacras, invertendo a hierarquia entre elas. Nesse cenário, foi elaborada a ideia de produzir um ensaio sobre os costaleros, atores essenciais de toda procissão, pois são eles os responsáveis pela sustentação física e movimentação dos andores com cenas da Paixão. Em um contexto caracterizado pela simultaneidade de estímulos sensoriais, mobilizando milhares de pessoas que se reúnem nas ruas estreitas da cidade, o que chamou minha atenção em relação aos costaleros era o contraste que eles produziam com o caráter espetacular das figuras religiosas. Como atores de um teatro às avessas, eles atuam por dentro de um compósito material que oculta seus corpos quase totalmente. Diante desse grupo, a questão que se colocava era: como traduzir em imagens algo que se caracteriza justamente por sua obliteração visual?

Cada andor, ou paso, é constituído por uma estrutura de vigas de madeira em formato retangular (2,3m x 5,3m em média) que é posteriormente recoberta por tecidos em todas as laterais, além de flores, efígies, velas e outros adereços na parte superior, chegando a pesar mais de duas toneladas (Rodríguez \& Bermúdez 2012). Para dar conta desse peso, os costaleros distribuem-se em grupos de 40 homens aproximadamente, subdivididos de acordo com sua estatura. Cada subconjunto, englobando cerca de seis homens lado a lado, é posicionado em uma das barras paralelas dispostas no interior do passo, chamadas de trabajaderas. Ali, os costaleros alinham suas nucas na madeira, fazendo com que a coluna vertebral, que sustenta seus corpos, seja também o eixo que sustentará o paso. Para reduzir o atrito entre a pele e a madeira, interpõe-se o artefato distintivo do grupo: o costal, uma peça retangular de tecido que envolve a cabeça e possui, na nuca, uma pequena almofada. No interior dos andores, um ambiente escuro e abafado, o costal chega quase a cobrir seus olhos - indicando como outros sentidos, como a audição, ganham preeminência na performance.

A ação dos costaleros se realiza com a ajuda dos capatazes, homens que lideram o grupo desde o lado de fora dos pasos. Vestidos em traje social, eles atuam como os olhos do coletivo, definindo o momento de levantar, de caminhar à frente, à direita ou à esquerda. Falando em voz alta, eles buscam dar ânimo ao grupo, exclamando através da estrutura dos andores: Venga de frente, valientes!

A conexão entre técnicas corporais, resistência física e motivação psicológica que resulta da relação entre capatazes e costaleros produz sua expressão máxima nos momentos conhecidos como Levantá dos pasos. Cada pausa feita com o andor para descansar ou substituir uma cuadrilla é acompanhada, em sua sequência, pela levantá do paso- momento de grande expectativa por demandar uma explosão de força dos costaleros. Nesse momento, o capataz convoca o grupo e aciona a memória de alguma pessoa próxima a eles, esteja ela doente ou tenha falecido 
recentemente, ou ainda fala em homenagem às imagens devocionais da Virgem ou do Cristo. Através da conjugação de memória, afeto e devoção, o capataz conclama para o salto da levantá, como um tipo de sacrifício dos costaleros, dizendo Todos por igual, valientes! Vámonos al cielo! - ao que eles respondem realizando um salto coletivo que eleva o andor e todos eles acima do chão.

A experiência de atuar em um papel ritual com grande estresse físico gera cicatrizes corporais nos mais aficionados - há homens que integram diferentes cuadrillas e participam de várias procissões durante a Semana. Trata-se de uma atividade marcada por uma divisão de papéis de gênero e uma sociabilidade masculina conjugada às representações de força e virilidade - enquanto as mulheres, por sua vez, são socializadas nos saberes necessários à confecção das roupas que cobrem as imagens sacras (Albert-Llorca 1995). Nesse sentido, o sacrifício corporal de Cristo, que é transposto esteticamente em suas efígies, parece ser emulado pelos seus devotos, que também possuem suas feridas produzidas na reencenação da via-crúcis.

Outra característica chave da prática ritual que oblitera os seres humanos para enfatizar os divinos, contrapondo alto e baixo, refere-se ainda ao caráter iniciático da performance costalera. Aos olhos de um pesquisador e estrangeiro, o interior dos pasos sevilhanos possui um inextrincável gradiente de mistério e desconhecimento. Fotografar sua ação e protagonistas era um desafio interessante porque interpunha duas "caixas-pretas" frente a frente. De um lado, os andores se apresentam como um compósito que reúne atores humanos e não humanos para seu funcionamento, uma tecnologia material e corporal com fins de produzir uma mensagem religiosa sensorial. Apenas os iniciados sabem de fato o que ocorre ali dentro. De outro lado, a câmera fotográfica também se vale de um sistema técnico que precisa da intervenção humana para produzir seu encantamento. Como ensinava Vilém Flusser (1998), a câmera é uma caixa na qual se inserem informações (input) e da qual se recebem outras informações (output), sem que o ator humano controle ou conheça integralmente o que se passa no interior dos dois extremos. Mais do que um agente autônomo, o fotógrafo seria um objeto instruído a fazer aquilo que a caixa-preta predefine como possível - aprendendo suas especificações, adequando-se às suas técnicas. Nossa percepção sendo codificada a partir das imagens que a câmera nos oferece. Nos dois casos, o empreendimento antropológico se produz ao seguir as condições específicas de visualidade e relação estabelecidas em meio a um grande ritual de passagem. São nessas passagens, betwixt and between, que podemos ampliar nosso conhecimento sobre o poder das imagens, suas tecnologias e rituais.

\section{REFERÊNCIAS BIBLIOGRÁFICAS}

ABC de Sevilha. s/d. "Las mejores fotografías de la Semana Santa de Sevilla de Juan Manuel Serrano”. Disponível em: https://sevilla.abc.es/sevilla/semana-santa/sevi-mejores-fotografias-semana-santa-40511740029-20200405083211_galeria.html\#imagen8, consultado em 2020-03-10.

Albert-Llorca, Marlène. 1995. "La Vierge mise à nu par ses chambrières". CLIO, Histoire, femmes et sociétés, 2 .

Aubier, Dominique. 1954. Seville en fête. Paris: Robert Delpire, 152 pp. incl. 140 illus.

Baeza, Antonio García. 2017. "El reflejo de la Semana Santa de Sevilla a través del cinematógrafo (1898-1960)”. In: Peña, José Roda (org.). XVIII Simposio sobre hermandades de Sevilla y su provincia. Sevilha: Cruzcampo. p.179-200. 
Bastide, Roger. 2006. “Variações sobre a porta barroca”. Novos estudos CEBRAP, (75), 129-137. https://doi.org/10.1590/S0101-33002006000200009

David, Jiménez. 2003. Sevilla Semana Santa. Eclipse libros; Cajasol.

Duncan, Carol. 2008. "Museu como ritual". Revista Poiésis, no 11, p.117-134.

Fontcuberta, Joan. 2013. A câmera de Pandora: a fotografi@ depois da fotografia. São Paulo: GG BR - Gustavo Gili.

Flusser, Vilém. 1998. Ensaio sobre a Fotografia: Para uma filosofia da técnica. Lisboa: Relógio d'Água.

García Rodero, Cristina. s/d. España Oculta : Hidden Spain. Magnum Photos. Disponível em https://www.magnumphotos.com/arts-culture/society-arts-culture/cristina-garcia-rodero-espana-oculta/?fbclid=IwAR3E1FO3N2BUOLv4PWj54vezW4updAP5Io3NEYCB4HzWgTuOnV5cBrjeq9Y, consultado em 2020-03-10.

Guran, Milton. 2011. "Considerações sobre a constituição e a utilização de um corpus fotográfico na pesquisa antropológica”. Discursos fotográficos, v.7, n.10, p.77-106.

Pereira, Edilson. 2019. "As imagens encarnadas entre mortos e vivos: notas etnográficas sobre ritual e retrato". Sociologia E Antropologia, 9 (2), 638-663. August 19.

.2018. “Caixa-preta sevilhana”. IX Prêmio Pierre Verger de fotografia. $31^{a}$ Reunião Brasileira de Antropologia, UnB.

2014. O Teatro da Religião: A semana santa em Ouro Preto vista através de seus personagens. Tese de doutorado em Antropologia Social. Rio de Janeiro: PPGAS/Museu Nacional/Universidade Federal do Rio de Janeiro.

2014a. "Anjos de Minas". VII Prêmio Pierre Verger de fotografia. 29a Reunião Brasileira de Antropologia, UFPB.

2010. "Tempo santo: uma festa em Ouro Preto". Mostra fotográfica do $34^{\circ}$ Encontro Anual da Associação Nacional de Pós-graduação e Pesquisa em Ciências Sociais - ANPOCS.

Rodríguez, Rafael M. \& Bermúdez, Moisés R. 2012. Locos del costal? Aproximación psicológica al costalero. Sevilla: Abec.

Romeiro, Adriana. 2009. Guerra dos 'Emboabas' 300 anos depois. Catálogo da Exposição. Palácio das Artes, Belo Horizonte, 2009.

Salanova, Concha Calvo. s/d. Brassaï (Gyula Halász). Museo Nacional Centro de Arte Reina Sofía. Disponível em : https://www.museoreinasofia.es/coleccion/obra/st-121, consultado em 2020-03-10.

Santaló, Álvarez C.; Rey, Maria J. Buxó; Becerra, Salvador Rodríguez (Coord.). 2003. La religiosidad popular: Hermandades, romerías y santuarios. Vol. 3. Barcelona: Anthropos Editorial.

Teulade, Anne. 2012. Le Saint Mis en Scène. Paris: Les Éditions du Cerf.

Turner, Victor. 2005. Floresta de Simbolos: Aspectos do ritual Ndembu. Niterói: EdUFF.

Verger, Pierre. 2007. Andalucía 1935. Madrid: Agencia Española de Cooperación Internacional.

Webster, Susan Verdi. 1998. Art and Ritual in Golden-Age Spain: Sevillian Confraternities and the Processional Sculpture of Holy Week. New Jersey: Princeton University Press.

\section{Photography and Ritual: An Essay about the Men and the Images of Passion}

This photo-essay presents the author's ethnographic research on the Holy Week in Ouro Preto, Brazil, and in the city of Seville, Spain. It analyzes the pre-eminence of images in the ritual context and de- 
scribes the use of visual research tools, especially photography. Discussing the limits of the photographic message, considering not only what it represents, but also what it may hide, the essay observes the ritual performance of the "costaleros" of Seville: the men who are responsible for carrying religious effigies during the procession. Like actors in an upside-down theatre, they act from within, hidden, alongside the scaffold that carry the Christian figures.

Keywords: Holy Week, Spain, religion, performance, photography, visual anthropology

Recebido em: 2018-12-30

Aceite em: 2020-05-19 